\title{
COMPROMETIMENTO COM O TRABALHO: PADRÕES EM DIFERENTES CONTEXTOS ORGANIZACIONAIS
}

\author{
Antônio Virgílio Bittencourt Bastos \\ Doutor em Psicologia pela Universidade de Brasília e Professor Titular do Departamento de Psicologia da UFBa. \\ E-mail: virgilio@ufba.br \\ Jairo Eduardo Borges-Andrade \\ Ph. D. em Sistemas Instrucionais pela Florida State University e Professor Titular \\ do Departamento de Psicologia Social e do Trabalho do Instituto de Psicologia da UnB. \\ E-mail: jeborges@linkexpress.com.br
}

\begin{abstract}
RESUMO
A pesquisa sobre comprometimento com a organização, a carreira e o sindicato tem requerido a análise de como o trabalhador estrutura, simultaneamente, seus comprometimentos diante desses três focos. Após identificar oito padrões de comprometimento em uma amostra de 1.029 trabalhadores de 20 organizações

brasileiras, este estudo analisa a distribuição desses padrões em quatro contextos organizacionais, diferenciados quanto ao nível e ao tipo de inovação organizacional implementada como demanda dos processos de transformação econômica e tecnológica. Os resultados apontam que a clássica organização burocrática diferencia-se significativamente das demais organizações inovadoras pela maior presença de padrões com baixo comprometimento organizacional.
\end{abstract}

\begin{abstract}
The research on organizational, career and union commitment has been requiring the analysis of how the worker simultaneously structures his or her commitments towards these three foci. After identifying eight commitment patterns in a sample of 1,029 workers from twenty Brazilian organizations, this study analyses the distribution of those patterns in four organizational contexts. These contexts were differentiated according to the level and type of organizational innovation which had been implemented as a demand from economic and technological processes. The results demonstrate that the classic bureaucratic organization is significantly different from the other innovative organizations: it includes more low organizational commitment patterns.
\end{abstract}

\section{PALAVRAS-CHAVE}

Comprometimento com o trabalho, inovação organizacional, comprometimento organizacional, comprometimento com a carreira, comprometimento com o sindicato. 


\section{INTRODUÇÃO}

As organizações, pressionadas por intensas mudanças em escala mundial, encontram-se em um processo acelerado e diferenciado de transformação de sua estrutura, formas de organização do trabalho e, em especial, estilos de gerenciar as relações sociais em seu interior. Esse processo global de reestruturação produtiva, cujos impactos se fazem sentir nas organizações, nas ocupações, nos sindicatos e na própria força de trabalho, buscaria superar o modelo tradicional e burocrático de estruturação e funcionamento organizacional.

\section{O PROCESSO DE MUDANÇA -} ECONÔMICA, TECNOLÓGICA, CULTURAL - É ALTAMENTE HETEROGÊNEO EM SEU DESDOBRAMENTO E NAS

\section{CONSEQÜÊNCIAS PARA}

\section{OS TRABALHADORES.}

Esse contexto de transformações - ambientais e organizacionais - implica significativas reestruturações das relações ou dos vínculos psicológicos postulados como necessários entre os indivíduos e as organizações. Surge, assim, o interesse que embasa o presente estudo em compreender o comprometimento do trabalhador com facetas de seu mundo de trabalho, considerando algumas inovações organizacionais. $\mathrm{O}$ objetivo mais específico deste artigo consiste em comparar padrões de comprometimento do trabalhador com a organização, a carreira e o sindicato em distintos formatos organizacionais.

De acordo com Marx (1992), estaria emergindo o denominado paradigma da "especialização flexível", que substitui uma economia de escala por uma de escopo com uso intensivo de tecnologia microeletrônica. Argumentase, todavia, que não se podem caracterizar as mudanças como um novo paradigma uma vez que a introdução da microeletrônica não rompe com os pilares básicos do taylorismo-fordismo. A realidade seria mais complexa, pois os dois modelos podem coexistir dependendo do país, do setor produtivo, do tipo de produção e do mercado de trabalho (Antunes, 1995). Para Leite (1994, p. 9), no entanto, "trata-se de um novo ideário que se incorpora ao discurso de diferentes atores - empresários, trabalhadores, educadores, administradores, associações de classe
- assumindo, em certa medida, a mesma dimensão paradigmática que a organização científica atingiu ao longo dos anos do pós-guerra".

Há uma diversidade de caminhos experimentados visando ao ajuste ao novo contexto que se delineia ou à intervenção no referido contexto. $\mathrm{O}$ processo de mudança- econômica, tecnológica, cultural - é altamente heterogêneo em seu desdobramento e nas consequiências para os trabalhadores. Ferramentas têm sido desenvolvidas na busca de maior flexibilidade organizacional, destacando-se, por exemplo, os programas de Just in Time e de Qualidade Total, usados com muita freqüência e que contam com ampla literatura disponível. Na realidade, desde o final dos anos 40, com a emergência do conceito de organização como sistema sociotécnico, experiências diversas vêm sendo desenvolvidas sobre como estruturar novas arquiteturas organizacionais em substituição ao modelo de burocracia mecânica, amplamente dominante e representativo do paradigma taylorista-fordista.

Buscando romper esse paradigma, os "novos" modelos organizacionais recebem diferentes rótulos: competitivos, ressaltando a capacidade de aprendizagem como qualidade básica (Foguel, 1992); empresas do terceiro tipo, possuindo um projeto interno compartilhado, menor hierarquia, oportunidades de trabalhos inteligentes e busca constante da melhoria e competitividade (Archier e Sérieyx, 1989); qualificantes, diminuindo níveis hierárquicos e organizando o trabalho em equipes autônomas (Zarifian, 1992 apud Fleury e Fleury, 1995); organizações de aprendizagem e organizações que aprendem (Argyris e Schön, 1996; Senge, 1990). Subjacente a todos esses modelos há o pressuposto de que o comprometimento da força de trabalho é um requisito fundamental para o sucesso das transformações, já que flexibilidade requer responsabilidade individual e corresponsabilidade entre indivíduos e equipes.

Para Antunes (1995), há, na realidade, um processo de heterogeneização e fragmentação da classe trabalhadora. Diminui o operariado fabril, mas aumenta o subproletariado, o trabalho com vínculo precário; amplia-se o contingente feminino, mas excluem-se os mais jovens e os mais velhos. Importante a distinção, feita pelo autor, entre trabalhadores "centrais" (os que permanecem em tempo integral na fábrica e com maior segurança) e "periféricos" (com menor ou nenhuma segurança e menor acesso às políticas de benefícios). Os paradoxos desse processo sugerem, assim, que elevado comprometimento não é um subproduto natural dos novos modelos organizacionais. Há forças que atuam para fragilizá-lo pela diminuição da segurança, pela redução de perspectivas de crescimento e pela transitoriedade de vínculos empregatícios.

Nesse contexto de profundas alterações estruturais 
e culturais nas organizações, quais são os impactos sobre o comprometimento do indivíduo com o trabalho? Mais especificamente, como se estruturam as relações de comprometimento do indivíduo com sua organização, sua carreira e seu sindicato - três aspectos que parecem centrais na demanda de lealdade do trabalhador? Tais questões revelam-se atuais e relevantes, já que o envolvimento ou comprometimento do trabalhador parece ser elemento crucial nas novas arquiteturas organizacionais emergentes. Elas são significativas para a prática e o conhecimento administrativo. O êxito das mudanças pretendidas depende, em grande parte, da forma como as organizações lidam com o envolvimento do trabalhador mediante estratégias que assegurem o compartilhamento de valores, de objetivos e de políticas que garantam trocas equânimes entre as partes.

Grande parte da literatura clássica concentrada na análise do conflito entre os comprometimentos com organização, carreira e sindicato estrutura-se na realidade das organizações burocráticas, cujas características básicas foram descritas por estudiosos como Weber. Para obtenção da lealdade do trabalhador, esse tipo de organização dispõe de mecanismos institucionalizados que, freqüentemente, implicam demandas antagônicas entre tais comprometimentos. Nessa realidade, surgiram os estudos sobre conflitos entre díades de compromissos: sindicato e empresa ou organização empregadora e profissão (a esse respeito, ver, por exemplo, Wallace, 1993). O tratamento simultâneo do comprometimento com a carreira, a organização e o sindicato foi empreendido por Bastos (1994) em uma pesquisa de corte transversal, buscando identificar padrões de comprometimento ou formas como os indivíduos estruturam seus vínculos diante desses três aspectos de seu mundo do trabalho.

Em geral, a pesquisa sobre comprometimento tem estabelecido relações entre variáveis pessoais, características do trabalho e políticas organizacionais com diferentes níveis de vínculo do trabalhador. Faltam, todavia, estudos que comparem a intensidade e a natureza desse vínculo entre tipos distintos de organizações, como discutido neste artigo. O presente relato de pesquisa observa a distribuição dos padrões de comprometimento em diferentes contextos organizacionais, ao procurar confrontar as organizações burocráticas tradicionais com as que estão inovando em seus processos de estruturação e gestão da força de trabalho. Nesse sentido, de forma exploratória, visa estabelecer possíveis vínculos entre os níveis macro (organizações diferenciadas quanto à presença de características burocráticas versus inovadoras) e microorganizacionais (tipo de vínculo desenvolvido pelo trabalhador), um desafio importante para a pesquisa na área, como bem assinalam Weick e Sandelands (1995).

\section{METODOLOGIA}

Ao empreender seu estudo, Bastos (1994) buscou implementar uma recomendação da pesquisa sobre comprometimento: estudar, em diversas organizações, múltiplos compromissos e seus preditores. Foram coletados, então, em 42 organizações de três estados brasileiros, dados sobre o comprometimento do trabalhador diante da organização, da carreira e do sindicato, além de um amplo conjunto de variáveis pessoais, da trajetória ocupacional, da natureza do trabalho e das políticas organizacionais de gestão de pessoas, apontado pela literatura como fatores que explicavam níveis diferenciados de comprometimento com os três

\section{O ENVOLVIMENTO OU}

\section{COMPROMETIMENTO DO}

\section{TRABALHADOR PARECE}

\section{SER ELEMENTO CRUCIAL}

\section{NAS NOVAS ARQUITETURAS}

\section{ORGANIZACIONAIS EMERGENTES.}

focos escolhidos. Utilizando parte desse banco mais amplo de dados, o presente artigo detém-se na análise de quatro contextos (casos) organizacionais distintos, em termos da existência de programas, implementados ou em fase de implementação, voltados para alteração em suas estruturas, organização do trabalho e práticas gerenciais.

O caso A representa a situação clássica de uma organização burocrática que, até o momento da coleta de dados, se encontrava fechada a quaisquer transformações semelhantes às de organizações mais dinâmicas ou de setores mais competitivos da economia. O padrão burocrático é representado pela reunião de quatro órgãos da administração pública centralizada, totalizando 103 trabalhadores, com idade média de 37,7 anos.

Três casos foram selecionados pelo critério de inovação: uma pequena empresa privada do setor metalúrgico (caso B), utilizando 31 sujeitos com idade média de 35,2 anos, uma fundação privada que mantém, dentro da mesma filosofia empresarial, duas prestadoras de serviços de saúde, aqui tratadas conjuntamente (caso C), totalizando 95 trabalhadores com idade média de 29,4, e uma empresa de economia mista, prestadora de serviços de telecomunicações (caso D), abrangendo 162 sujeitos com idade média de 35,2 anos. Para seleção desses casos, adotou-se como critério de inovação o fato de apresentarem iniciativas de 
ajuste congruentes com as transformações atuais do mundo do trabalho, em graus e modalidades diferenciadas, e que implicavam a adesão às ferramentas e soluções gerenciais surgidas no âmbito pós-fordista (por exemplo, Qualidade Total, Reengenharia e Just in Time). Considerou-se, adicionalmente, o acesso a um contingente representativo de seus empregados, permitindo uma análise da variabilidade dos padrões de comprometimento descritos mais adiante.

\section{FORAM IDENTIFICADOS E}

\section{INTERPRETADOS OITO PADRÕES DE COMPROMETIMENTO, FORMANDO QUATRO PARES ANTAGÔNICOS.}

Para identificar tais padrões, utilizou-se um questionário com itens fechados contendo três escalas Likert, previamente validadas e cuja confiabilidade era elevada (Bastos, 1992):

- Organização: escala de Mowday et al. (1979), validada no Brasil por Borges-Andrade et al. (1989), em versão reduzida de nove itens que enfatizam um vínculo afetivo de identificação do indivíduo com valores e objetivos organizacionais, sua disposição em permanecer como membro da organização e defendê-la.

- Carreira: escala, proposta e validada por Blau (1985), de sete itens que avaliam o grau de identificação com os valores da ocupação, o desejo de continuar e a congruência entre escolha da carreira e vocação.

- Sindicato: versão reduzida de dez itens (Fukami e Larson, 1984), construída a partir da escala inicial de Gordon et al. (1980) e que apresenta o mesmo conteúdo da escala de comprometimento com a organização, mas com foco no sindicato.

Com base nessas três medidas (com escores variando de 1 a 7), adotaram-se procedimentos de cluster analysis (método wards) do SPSS para Windows. Buscou-se, ao longo dessa análise, a solução que apontasse padrões qualitativamente distintos. Foram identificados e interpretados oito padrões de comprometimento, formando quatro pares antagônicos utilizados no presente estudo. Uma descrição mais abrangente e detalhada de cada padrão foi realizada por Bastos e Borges-Andrade (1995). Sua rápida caracterização, com base na Figura 1, é apresentada a seguir.

O grupo denominado anti-sindicato (1), $16 \%$ da amostra estudada, destaca-se pela acentuada discrepância entre os escores positivos de comprometimento com a organização e a carreira e negativos diante do sindi- cato, indicando forte restrição ao sindicato, tanto na dimensão instrumental (avaliação de sua contribuição) quanto na afetiva (internalização de seus valores e metas). No segundo grupo - o sindicalista (2) -, em oposição ao anterior, é clara a tendência dos membros em eleger o sindicato como o aspecto do trabalho ao qual mais fortemente se vinculam. Este é um grupo menos numeroso que o anterior (8\% da amostra). O terceiro cluster foi denominado profissional (3), constituindo-se de indivíduos que se apresentam comprometidos apenas com sua carreira, tendo escores moderadamente negativos com a organização e o sindicato. Ele também abarca uma pequena porção da amostra (9\%), aproximando-se da clássica definição proposta por Gouldner (1958). Em oposição, há um grupo (8\%) que se destaca pelo reduzido comprometimento com a carreira, associado a um padrão de dupla lealdade na relação organização-sindicato. Ele foi rotulado de descomprometido com a carreira (8).

Os profissionais-sindicalistas (4) constituem o grupo numericamente menos expressivo (2\%). Combinam elevado compromisso com a carreira e o sindicato, associado a um elevado descompromisso com a organização, que pode chegar a ser um claro antagonismo. Padrão oposto ao desse grupo (com 11\% da amostra) encontra-se no cluster rotulado de localista (7), em uma alusão ao constructo proposto por Gouldner (1958). São indivíduos cujo comprometimento com a organização é moderadamente positivo, sendo negativos seus vínculos com carreira e sindicato. Finalmente, a última díade contrapõe os grupos descomprometido (5) e comprometido (6) com os três aspectos do trabalho analisados. O cluster 5 é integrado por $11 \%$ da amostra, com escores médios negativos nas três medidas de comprometimento, especialmente em relação ao sindicato. $\mathrm{O}$ cluster 6 é o numericamente mais expressivo (36\% dos casos), apresentando um elevado comprometimento com a carreira e a organização e moderadamente positivo com o sindicato.

A distribuição desses oito padrões, nos quatro casos estudados, foi observada por meio de tabelas de contingência (crosstabs). Análises de variância e de correlações foram ainda empregadas para comparar os diferentes contextos organizacionais nas diversas medidas de comprometimento. Além disso, nas organizações inovadoras, foram realizadas entrevistas com dirigentes para caracterização do processo de mudança, complementadas com análise de documentos sobre sua filosofia, missão e organograma.

\section{RESULTADOS}

Os três contextos organizacionais escolhidos como inovadores estão caracterizados nos Quadros 1, 2 e 3. 
Figura 1 - Padrões de comprometimento no trabalho

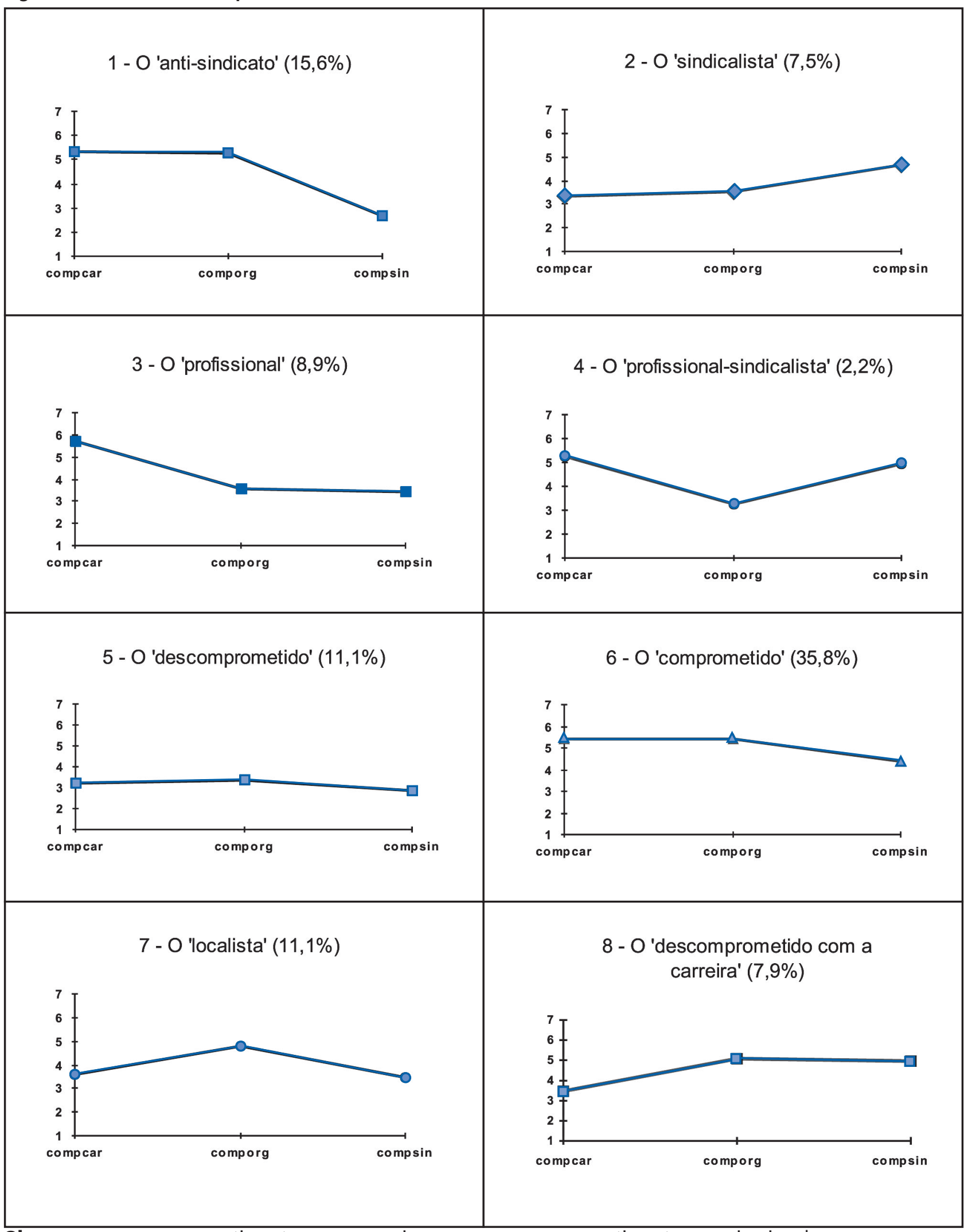

Obs.: compcar - comprometimento com a carreira; comporg - comprometimento organizacional; compsin - comprometimento com o sindicato. 
O caso B constitui-se de uma empresa metalúrgica de pequeno porte que vivera sérios problemas de qualidade em seu produto. A devolução de um estoque desse produto originou o processo de mudança. Ainda estava exposto na empresa um quadro com o documento de devolução dos produtos e a assinatura de vários trabalhadores e da diretoria, comprometendo-se a não deixar que isso voltasse a ocorrer. Os elementos inovadores, adotados a partir da crise, constam no Quadro 1.

As duas organizações que integram o caso $\mathrm{C}$ ligamse a uma mesma fundação de direito privado, funcionam em instalações físicas contíguas (um hospital e um centro de saúde ocupacional) e utilizam uma tecnologia empresarial própria, apresentada no Quadro 2.

Finalmente, a empresa (D), de grande porte, integrava o sistema nacional brasileiro de empresas de telecomunicações e suas características inovadoras estão descritas no Quadro 3.

A distribuição dos padrões de comprometimento, nos quatro contextos organizacionais selecionados, pode ser observada na Figura 2. As diferenças mostram singularidades na forma em que as três organizações "inovadoras" se distanciam da organização burocrática tradicional.

\section{Quadro 1 - Características inovadoras do caso B - Empresa metalúrgica}

- Adoção de organização do trabalho que busca flexibilidade segundo o modelo Just in Time.

- Automatização de todo o processo produtivo e estruturação do ambiente de trabalho segundo o modelo japonês (por ex.: frases estimulando a qualidade, acesso irrestrito do trabalhador aos estoques e equipamentos, sinalização por meio de cartões coloridos, abolição de grande parte de divisórias que separavam a gerência dos trabalhadores).

- Uso do kanban, que estabelece a tarefa a ser realizada e que leva o trabalhador a circular por várias máquinas para completá-la, rompendo, de alguma forma, a fragmentação da linha de montagem tradicional.

- Abolição do nível de supervisão, diminuindo a hierarquia na empresa, e a transformação do organograma de uma estrutura piramidal para círculos concêntricos.

- Implementação de programas culturais (peças de teatro, concertos musicais e palestras), de lazer (práticas orientais como o tai-chi-chuan e a meditação) e de complementação educacional.

- Realização de encontros mensais entre todos os trabalhadores para, além da atividade cultural, discutirem a situação financeira da empresa, com todas as demandas recebidas e atendidas e seu decorrente fluxo de recursos.

\section{Quadro 2 - Características inovadoras do caso C - Fundação de saúde}

- Tecnologia empresarial calcada na descentralização planejada: uso de parceria interna ou empreendedores. Internamente, os negócios (todos os setores da organização) constituem centros de custos independentes que vendem serviços e uso de equipamentos entre si.

- Os parceiros têm autonomia para buscar a qualidade dos serviços via montagem da equipe e lucratividade da atividade. O empreendedor participa dos lucros gerados pelo negócio, além de possuir uma remuneração básica.

- O sistema de parceria é definido pela fundação como um acordo moral e psicológico consubstanciado em um plano de ação que define o negócio, sua filosofia, resultados desejados, estrutura e partilha de resultados e, segundo ela mesma, "...gerando, assim, um comprometimento com o todo".

- A essa tecnologia associa-se forte preocupação com a qualidade dos serviços prestados e ênfase especial na comunicação e diálogo intra e interequipes.

- Rompimento do modelo hierarquizado de desenho organizacional, aproximando-se de um modelo de redes interorganizacionais. 
O perfil que distingue a administração pública centralizada (caso A), ou organização burocrática clássica, apresenta elevada concentração de seus funcionários $(68 \%)$ nos padrões caracterizados por reduzido comprometimento organizacional (2, 3, 4 e 5 na Figura 1). Nos padrões descomprometido e profissional, estão mais de 50\% dos sujeitos: para esse contingente, ou se está comprometido apenas com a carreira ou não se está comprometido com nenhum dos aspectos estudados. Encontrou-se, nesse caso, o mais baixo escore médio de comprometimento organizacional $(X=3,6$; $\mathrm{dp}=1,2)$. Embora o compromisso com o sindicato não seja alto, observa-se que os percentuais de sujeitos nos padrões sindicalista e profissional-sindicalista são bastante superiores às demais organizações - e mesmo em relação à amostra original de Bastos (1994) -, ou seja, há, proporcionalmente, mais indivíduos que se vinculam ao sindicato em clara e forte oposição à organização. Verifica-se essa polarização também entre carreira e organização. Embora haja níveis moderadamente positivos de comprometimento com a carreira ( $62 \%$ dos casos nos grupos 1, 3, 4 e 6), os sujeitos dividem-se entre os que conciliam - ou não - comprometimento com a carreira e a organização.

A segunda organização (B) apresenta elevada concentração de trabalhadores nos grupos comprometido $(48 \%)$ e localista (19\%). Associado ao reduzido número de sujeitos com baixo comprometimento organizacional, tal dado explica o fato de ter-se encontrado, nessa empresa, o segundo mais elevado escore médio de comprometimento com a organização $(X=5,2)$ associado ao menor índice de variabilidade $(\mathrm{dp}=0,7)$ dentre todas as empresas estudadas. A presença do sindicato é menos importante, quer observando-se a participação dos trabalhadores nos grupos de elevado com- promisso com esse foco, quer constatando-se que a média geral tende a ser moderadamente negativa $(\mathrm{X}=$ $3,9, \mathrm{dp}=0,95)$. Não existe, também se considerando o total dos casos, um antagonismo entre o comprometimento com a organização e o sindicato (correlação positiva de $0,3, \mathrm{p}<0,05)$. Outro dado importante dessa organização refere-se ao escore elevado de comprometimento com a carreira $(X=4,7, d p=1,2)$, mesmo

\section{A POLARIDADE ORGANIZAÇÃO-} SINDICATO DEVE-SE TANTO

A FATORES PESSOAIS, QUE APROXIMAM OU AFASTAM OS INDIVÍDUOS DO SINDICATO, QUANTO A ASPECTOS REFERENTES À NATUREZA DAS RELAÇÕES
ENTRE AS DUAS ENTIDADES.

tendo maior participação de trabalhadores industriais e reduzido número de profissionais de nível superior, composição oposta à da organização anterior. Diferentemente das outras organizações analisadas, constata-se, nessa empresa, uma associação positiva entre o comprometimento com o sindicato e com a carreira $(\mathrm{r}=0,4, \mathrm{p}<0,001)$. Os dados estatísticos são bastante congruentes com as impressões obtidas durante o processo de coleta de dados. Ao lidar com uma população

\section{Quadro 3 - Características inovadoras do caso D - Empresa de telecomunicação}

- Amplo engajamento na implementação do programa de Qualidade Total, com todos os componentes que caracterizam esse modelo de intervenção nos processos organizacionais. Intenso programa de treinamento nos princípios da Qualidade Total buscava dar suporte ao programa.

- Enxugamento da estrutura e terceirização de serviços.

- Em alguns setores, observavam-se também experiências similares à organização (B), no tocante à mudança nas relações de trabalho, busca de maior autonomia e grupos de reflexão sobre o trabalho.

- A organização possuía uma história longa de excelência organizacional. Administrada por profissionais com destaque na comunidade, a empresa sempre procurava desenvolver políticas que priorizassem a qualificação de seu corpo funcional.

- Havia um sindicato estruturado e atuante (segundo padrão comum às estatais brasileiras no período da pesquisa), filiado à Central Única dos Trabalhadores (CUT) que, a julgar por algumas de suas publicações, mantinha uma postura firme de denúncia das condições de trabalho e de reivindicação de acesso a informações da empresa nos assuntos de interesse dos trabalhadores. 
operária, pôde-se observar sua grande preocupação em responder o questionário de forma completa, cuidadosa e rigorosa; foram inúmeras as manifestações verbais de que os respondentes se encontravam em um contexto "singular", que lhes garantia autonomia e respeito.

A quarta organização (D) é a que apresenta o mais elevado contingente de trabalhadores no padrão comprometido (57\%), sendo insignificantes os percentuais de pessoas nos padrões caracterizados por baixo comprometimento com a organização. Esse dado reflete-se no mais alto escore de comprometimento organizacional, dentre todas as empresas estudadas $(X=5,3, \mathrm{dp}=$ $0,9)$. Nela encontra-se, ainda, o mais elevado escore médio de comprometimento com a carreira $(X=4,9)$, embora seja maior a dispersão dos sujeitos $(\mathrm{dp}=1,2)$. Há, em geral, forte associação positiva entre comprometimento com a organização e com a carreira $(r=0,5$; $\mathrm{p}<0,001)$. A presença de um sindicato forte e atuante traduz-se no escore médio mais elevado de comprometimento com esse foco dentre as quatro organizações em discussão $(X=4,2, d p=0,98)$, mas que não pode ser considerado elevado. As associações do comprometimento sindical, tanto em relação à carreira quanto à organização, são próximas de zero.

Os dados relativos às organizações (B) e (D), ambas vivenciando processos de mudanças mais consolidados, revelam um possível efeito das novas estratégias organizacionais no fortalecimento do compromisso com a organização e, por extensão, com a carreira. Na organização (B) percebe-se uma relação mais direta entre o novo formato organizacional e o comprometimento do trabalhador. Por representarem mudanças extremamente profundas e realizadas em uma empresa de pequeno porte, elas exerceram um impacto muito forte na vida dessa empresa metalúrgica. O elevado comprometimento constatado na organização (D), todavia, não pode ser creditado tão diretamente ao programa de Qualidade Total, em curso no momento da pesquisa. É mais provável que ele se deva a uma cultura sedimentada ao longo da história da empresa estatal de telecomunicação que, como se afirmou, gozava de amplo prestígio na comunidade.

Em relação à terceira organização $(C)$, as diferenças diante da organização tradicional não caminham completamente na direção observada nas duas anteriores. É verdade que nela se verifica um nível mais elevado de comprometimento com a organização (X = 4,7), comparando-se com a organização (A), este, porém, é ligeiramente inferior ao constatado nas organizações (B) e (D) e apresenta maior variabilidade $(\mathrm{dp}=1,1)$. Comparativamente a essas duas organizações, é bem menos expressivo o contingente de comprometidos $(25 \%)$ e maior o de descomprometidos (15\%). Outro vetor diferenciador do conjunto de prestadoras de serviço de saúde é a tendência antisindicato mais forte. Isoladamente, este é o padrão em que se apresenta o maior número de trabalhadores $(27 \%)$. Embora não seja objetivo deste estudo avaliar quão bem-sucedidas são as experiências inovadoras na modificação dos comprometimentos, é importante salientar que a filosofia gerencial de parceria estava sendo aplicada em um processo de reestruturação de uma organização já existente (no caso do hospital) e que funcionou, durante muitos anos, baseada em uma

Quadro 4 - Síntese dos resultados comparativos dos padrões de comprometimento nos quatro contextos organizacionais

\begin{tabular}{|c|c|c|c|}
\hline $\begin{array}{l}\text { A: Administração } \\
\text { pública direta }\end{array}$ & $\begin{array}{l}\text { B: Empresa } \\
\text { metalúrgica }\end{array}$ & $\begin{array}{l}\text { C: Fundação } \\
\text { de saúde }\end{array}$ & $\begin{array}{l}\text { D: Empresa de } \\
\text { telecomunicação }\end{array}$ \\
\hline $\begin{array}{l}\text { - Baixo } \\
\text { comprometimento } \\
\text { organizacional } \\
\text { - Predominância de } \\
\text { "descomprometidos" } \\
\text { - Maior participação de } \\
\text { "comprometidos } \\
\text { apenas com a carreira" } \\
\text { - Presença relativamente } \\
\text { mais alta de } \\
\text { "sindicalistas" e de } \\
\text { "profissionais- } \\
\text { sindicalistas" }\end{array}$ & $\begin{array}{l}\text { - Alto comprometimento } \\
\text { organizacional } \\
\text { - Elevada concentração } \\
\text { de "comprometidos" } \\
\text { - Forte presença de } \\
\text { "localistas" } \\
\text { - Baixo } \\
\text { comprometimento } \\
\text { com o sindicato } \\
\text { - Alto comprometimento } \\
\text { com a carreira }\end{array}$ & $\begin{array}{l}\text { - Presença forte de } \\
\text { "anti-sindicato" } \\
\text { - Menor contingente de } \\
\text { "comprometidos" } \\
\text { entre os três contextos } \\
\text { inovadores } \\
\text { - Maior contingente de } \\
\text { "descomprometidos" } \\
\text { entre os três contextos } \\
\text { inovadores }\end{array}$ & $\begin{array}{l}\text { Maior } \\
\text { comprometimento } \\
\text { organizacional } \\
\text { - O mais elevado } \\
\text { contingente de } \\
\text { "comprometidos" } \\
\text { Mais elevado } \\
\text { comprometimento } \\
\text { com a carreira } \\
\text { Relativamente mais } \\
\text { alto comprometimento } \\
\text { com o sindicato }\end{array}$ \\
\hline
\end{tabular}


Figura 2 - Distribuição percentual dos oito padrões de comprometimento nas quatro organizações estudadas

Organização (A): Administração pública direta

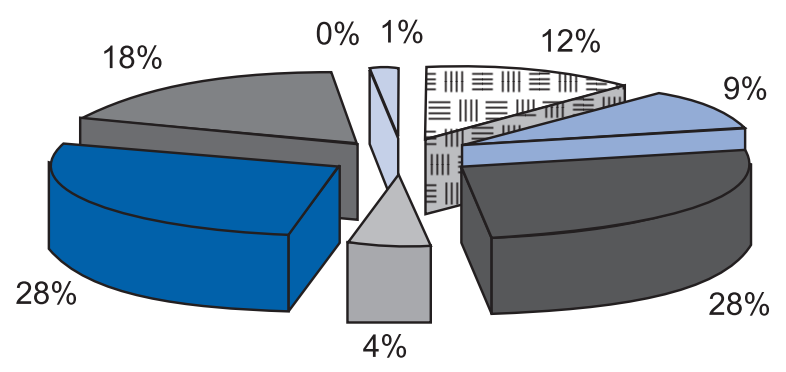

Organização (B): Empresa metalúrgica

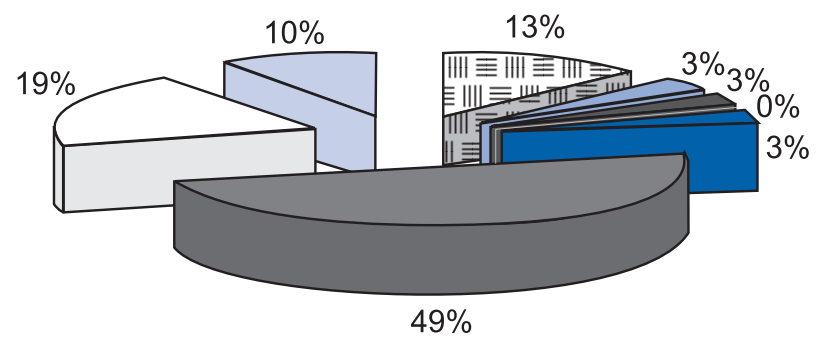

Organização (C): Fundação de saúde

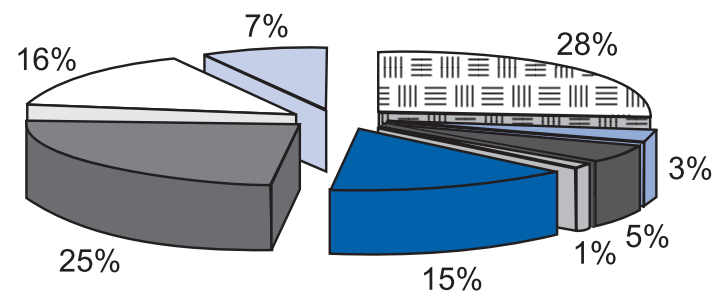

Organização (D): Empresa de telecomunicação

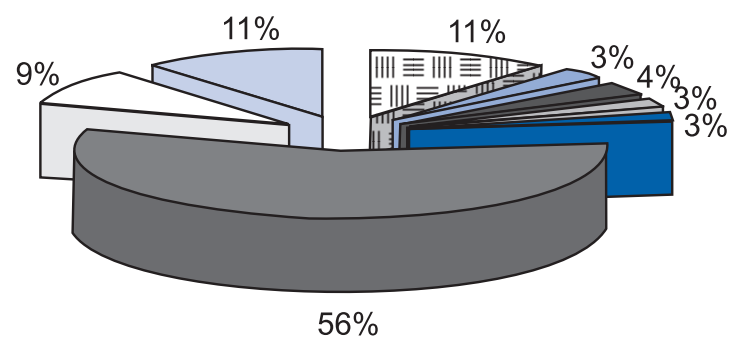

奉 Anti-sindicato

$\square$ Sindicalista

Profissional

Prof.-sindicalista

Descomprometido

Comprometido

Localista

Desc. carreira 
estrutura centralizada convencional. Enfrentavam-se, no momento da pesquisa, dificuldades naturais pela "mudança profunda de mentalidade" exigida da equipe (especialmente dos empreendedores) e pela complexidade de articulá-la em torno de metas decorrentes da filosofia geral.

O Quadro 4 sintetiza os principais resultados comparativos entre os quatro contextos organizacionais estudados.

\section{A POLARIDADE ORGANIZAÇÃO-}

\section{CARREIRA, POR SUA VEZ, LIGA-SE}

\section{A PROCESSOS INTERNOS POR MEIO}

\section{DOS QUAIS AS ORGANIZAÇÕES}

\section{ESTRUTURAM E DESENHAM}

\section{SEUS POSTOS DE TRABALHO.}

É importante salientar, no entanto, que a associação entre padrões de comprometimento e tipo de organização burocrática tradicional, apresentada pela organização (A), não se estende a todas as organizações públicas da amostra original de Bastos (1994). Um caso merece destaque, embora não seja um dos que foram originalmente selecionados para esta análise. Trata-se de um órgão suplementar de uma instituição universitária, voltado para a pesquisa e prestação de serviços a organizações, subordinado a mecanismos centralizados de gestão pública em sua força de trabalho. Nele, contudo, o nível de comprometimento organizacional é tão alto quanto o da organização (D) e o de comprometimento com a carreira é superior ao das três organizações analisadas como inovadoras. O escore mais baixo é o de comprometimento com o sindicato, embora este seja forte e atuante na universidade. Revela-se um contexto em que os objetivos profissionais parecem ser compatíveis às metas da organização, havendo alta correlação entre esses dois compromissos, o que é consistente com um resultado relatado na meta-análise de Wallace (1993). Nesse órgão, variáveis ligadas à sua cultura, sedimentada ao longo dos muitos anos em que foi formada sua equipe técnica, provavelmente explicam os níveis de comprometimento observados. A valorização da missão organizacional, um forte elemento dessa cultura, pode ser um importante fator para entender esse caso singular, além do sentimento de estar vinculado a uma organização significativa e socialmente importante, como apontam dados de Brandão (1991) e BorgesAndrade et al. (1989).

\section{CONCLUSÃO}

Embora a literatura técnica especializada aponte, para o sucesso dos novos modelos organizacionais, a necessidade de uma mão-de-obra comprometida com objetivos e metas, a literatura científica carece de dados sobre possíveis associações entre mudanças organizacionais e comprometimento no trabalho.

Os resultados apresentados evidenciam congruência entre as características dos contextos estudados e os padrões de comprometimento que neles emergiram. A organização burocrática revela padrões bem mais frágeis de comprometimento, considerando-se os possíveis interesses que ela, ou qualquer organização, possa ter em termos de sua sustentabilidade. Por outro lado, os três contextos inovadores, apesar de terem indicadores mais positivos nessa direção, não se caracterizam de forma homogênea quanto aos padrões de comprometimento, e essa diferença pode ser produto, sobretudo, da importância psicológica atribuída ao sindicato e do nível de profissionalização das ocupações predominantes.

A polaridade organização-sindicato deve-se tanto a fatores pessoais (ideológicos), que aproximam ou afastam os indivíduos do sindicato, quanto a aspectos referentes à natureza das relações entre as duas entidades (mais integradas ou conflituosas). Nesse sentido, insere-se como uma das vertentes de mudança organizacional, no atual contexto, a busca de relações mais cooperativas com os sindicatos em torno de projetos que conciliem os interesses empresariais e os dos trabalhadores. Aliar esses dois comprometimentos, portanto, pode significar um passo importante no processo de aproximação empresa-sindicato.

A polaridade organização-carreira, por sua vez, liga-se a processos internos por meio dos quais as organizações estruturam e desenham seus postos de trabalho. Como parte das transformações que marcam as empresas inovadoras, seria esperada a condução de processos de reorganização do trabalho que ofereçam maior congruência entre as expectativas profissionais de seus membros e as tarefas que efetivamente desempenham. Comprometimento positivo diante desses dois focos seria um indicador do sucesso com que tal objetivo está sendo atingido.

Em síntese, o nível positivo de comprometimento com os três focos estudados, a exemplo daquele encontrado no padrão comprometido, pode significar um padrão mais congruente com o que se espera das organizações inovadoras.

O exame das organizações selecionadas agrega evidências relevantes para a compreensão dos determinantes dos padrões de comprometimento identificados. As diferenças encontradas no peso dos diferentes padrões entre as organizações são suficientemente fortes e des- 
tacam o impacto do contexto de trabalho no comprometimento do trabalhador, embora a presença, em uma mesma organização, de indivíduos com distintos padrões fortaleça a determinação pessoal ou individual. Deve-se ressaltar, contudo, que mecanismos de seleção, avaliação, treinamento e marketing interno - utilizados pelas próprias organizações - podem explicar parte da associação encontrada, não se podendo atribuí-la exclusivamente aos aspectos da organização do trabalho e das políticas organizacionais inovadoras que diferenciam os casos selecionados.

Finalmente, vale destacar que os dados apresentados constituem explorações iniciais, fornecendo pistas para futuros estudos cujos delineamentos possam possibilitar: a) o acompanhamento de tais mudanças ao longo de determinados períodos de tempo, para obterem-se maiores evidências de como interagem os processos de reestruturação e inovação organizacionais (nível macro) e o comprometimento do trabalhador (nível micro); b) a utilização de uma abordagem multinível, para verificarem-se efeitos top-down e bottom-up - conforme proposição de Klein e Koslowski (2000) - entre esses fenômenos e adquirir maior segurança sobre as efetivas relações entre variáveis dos níveis micro e macro. Outra recomendação para pesquisas posteriores seria a de incluir dados que permitam avaliar as conseqüências dos padrões de comprometimento para as organizações estudadas. $\bigcirc$

\section{REFERÊNCIAS BIBLIOGRÁFICAS}

ANTUNES, R. Adeus ao trabalho? Ensaios sobre as metamorfoses e a centralidade do mundo do trabalho. São Paulo/Campinas : Cortez, Ed. da Unicamp, 1995

ARCHIER, G., SÉRIEYX, H. A empresa do $3^{\circ}$ tipo. São Paulo : Nobel, 1989

ARGYRIS, C., SCHÖN, D. A. Organizational learning II: theory, method, and practice. Reading, MA : Addison-Wesley, 1996.

BASTOS, A. V. B. Medidas de comprometimento no contexto de trabalho: um estudo preliminar de validade discriminante. Psico, v. 24, n. 2, p. 29-48, 1992.

BASTOS, A. V. B. Comprometimento no trabalho: a estrutura dos vínculos do trabalhador com a organização, a carreira e o sindicato. Tese (Doutorado) - Instituto de Psicologia, Universidade de Brasília, 1994.

BASTOS, A. V. B., BORGES-ANDRADE， J. E. Comprometimento no trabalho: identificando padrões de comprometimento do trabalhador com a organização, a carreira e o sindicato. Revista Brasileira de Administração Contemporânea, v. 1, n. 6, p. 205-218, 1995.

BLAU, G. J. The measurement and prediction of career commitment. Journal of Occupational Psychology, v. 58, p. 277-288, 1985.
BORGES-ANDRADE, J. E., AFANASIEFF, R. S., SILVA M. S. Mensuração de comprometimento organizacional em instituições públicas. In: REUNIÃ̃ ANUAL DE PSICOLOGIA, 19., 1989, Ribeirão Preto. Programa da XIX Reunião Anual de Psicologia. Ribeirão Preto : Sociedade Brasileira de Psicologia, 1989. p. 236

BRANDÃO, M. G. A. Comprometimento organizacional na administração pública: um estudo de caso em uma instituição universitária. Dissertação (Mestrado) Escola de Administração, Universidade Federal da Bahia, 1991.

FLEURY, A., FLEURY, M. T. L. Aprendizagem e inovação organizacional: as experiências de Japão, Coréia e Brasil. São Paulo : Atlas, 1995

FOGUEL, S. A década da aprendizagem. Odebrecht Informa, v. 18, n. 50, p. 59-60, 1992.

FUKAMI, C. V., LARSON, E. N. Commitment to company and union: parallel models. Journal of Applied Psychology, v. 69, n. 3, p. 367-371, 1984.

GORDON, M. E., PHILPOT, J. W., BURT, R. E. et al. Commitment to the union: development of a measure and an examination of its correlates. Journal of Applied Psychology - Monograph, v. 65, n. 4, p. 479499, 1980.

GOULDNER, A. W. Cosmopolitans and locals: towards an analysis of latent social roles - II. Administrative Science Quarterly, v. 2, p. 444-480, 1958.
KLEIN, K. J., KOSLOWSKI, S. W. J. Multilevel theory, research, and methods in organizations: foundations, extensions, and new directions. San Francisco : Jossey-Bass, 2000. p. 3-346.

LEITE, M. P. O futuro do trabalho: novas tecnologias e subjetividade operária. São Paulo: Scritta /Fapesp, 1994.

MARX, R. Processo de trabalho e grupos semiautônomos: a evolução da experiência sueca de Kalmar aos anos 90. RAE - Revista de Administração de Empresas, v. 32, n. 2, p. 36-43, 1992.

MOWDAY, R. T., STEERS, R. M., PORTER, L. W. The measurement of organizational commitment. Journal of Vocational Psychology, v. 14, p. 224-247, 1979.

SENGE, P. M. The fifth discipline: the art and practice of learning organization. New York : Double Day/ Currency, 1990.

WALLACE, J. E. Professional and organizational commitment: compatible or incompatible? Journal of Vocational Behavior, v. 42, p. 333-349, 1993.

WEICK, K. E., SANDELANDS, L. E. Social behavior in organizational studies. Journal for the Theory of Social Behavior, v. 20, n. 4, p. 323-346, 1995 